\title{
New Generation Expression Host System- Aiming high for commercial production of recombinant protein
}

\author{
${ }^{1}$ Mahendra K. Verma, ${ }^{2}$ Yogendra K. Verma \\ ${ }^{I}$ Department of Biotechnology, R.V.R. \& J.C. College of Engineering \\ Guntur, Andhra Pradesh, India- 522019 \\ ${ }^{2}$ Department of aerobic Microbiology, All India Institute of Medical Science \\ New Delhi, India-110029
}

\begin{abstract}
The global requirements of recombinant protein have increased exponentially in last one decade in various aspects. The commercial production of recombinant proteins requires an ideal host expression system which effectively meets the demand. Numerous host expression systems have been used to achieve level of expression. Escherichia coli BL21 (DE3) have been used ideally for expression of numbers of recombinant proteins from many decades. Though, Escherichia coli Bl21 is quite enough to express recombinant protein in higher fold but often get fails to achieve over expression of protein as essential requirement for today demand. Recently many engineered strains have been implemented in order to bring expression level as per requirement. The complications which arise in the expression of recombinant protein are mainly due to codon bias or inability of vector promoter to utilize host polymerase; while for over-expression of recombinant proteins often inhibit itself due to protein toxicity in conventional expression host systems. Escherichia coli C41 (DE3), Escherichia coli C43 (DE3) and Escherichia coli Rosetta are the refined and engineered strains which have shown over-expression of recombinant protein in recent time. These strains are designed to overcome the complication often limits conventional expression system.
\end{abstract}

Keywords: Codon bias, promoter, Expression, host expression system, Recombinant protein

\section{Introduction}

The advancement in technologies in biological science, molecular biology, recombinant DNA technology and protein engineering have equipped human to understand biomolecules at molecular level and refine them as per requirements[1]. These refined molecules have been used significantly in medicine, industrial application and for analytical applications since long time. The protein molecules which essentially used as enzymes have made many revolutions in medical filed and more ever in industry. Enzymes which are basically proteins have enormous capability of catalysis, which have been employed for the treatment of various diseases, optimization of different conventional industrial process and in design of many diagnostic $[2,3]$. To achieve following, enzyme must produced in sufficient quantity with intact activity [4]. To meet the demand in industrial sector and medical application different methods were opted for these amazing molecules, more specifically molecular cloning and expression in microbial host systems $[5,6]$. The benefits of microbial host systems, they are easy to grow and manipulate as per requirements. Rather than prokaryotic protein, eukaryotic protein exhibits even more complications while expressions in the prokaryotic host system. This is due to codon bias which interferes in process of translation while selecting t-RNA form amino acid pool as difference in codon and lacking of post translational machinery [7, 8]. Recently few host system have been designed to overcome with these complication like Pichia pastoris. An alternative approach to express the eukaryotic protein is codon optimization which needs few universal codons especially designed for the protein from eukaryotic source $[9,10]$.

\section{Commercial Demand of recombinant proteins}

The commercial application of recombinant proteins is ubiquitous, protein as enzymes in Industrial applications; Food Processing, Detergents, Beverages, Leather processing are few sector which have explored significance of these molecules. The global production of these enzymes is rapidly increasing which needs large scale production of these potent molecules [ $\left[\begin{array}{lll}1 & 12 & 13\end{array}\right]$. 


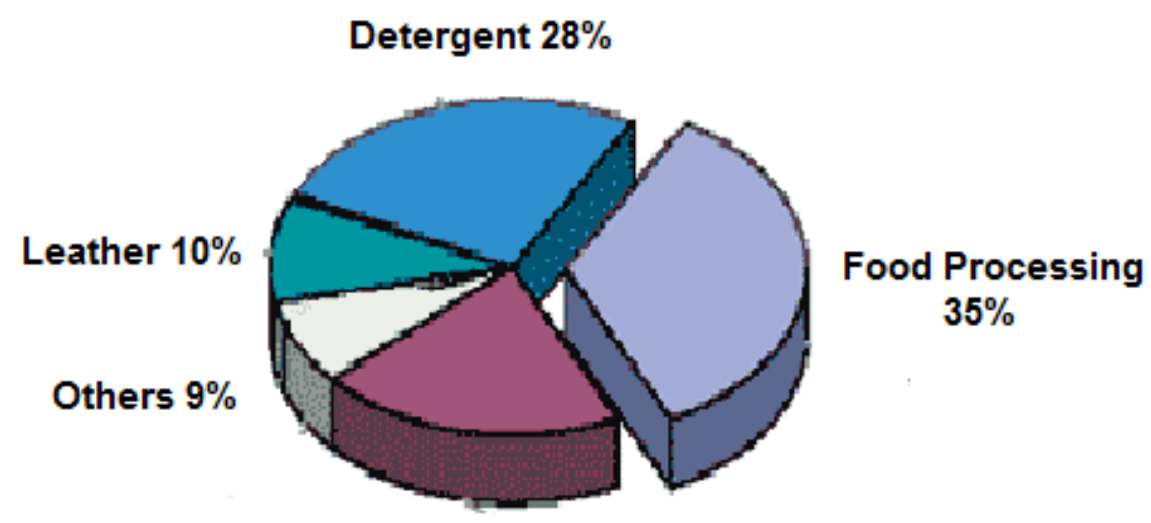

Beverages 23\%

Fig 1: Industrial demand of enzymes worldwide in different sectors

Simultaneously with industrial applications, recombinant proteins used maximally as therapeutics used for treatment of number of diseases. These proteins are in clinical use for variety of disease like heart attacks, strokes, cystic fibrosis, diabetes anemia, and hemophilia etc [14 15].

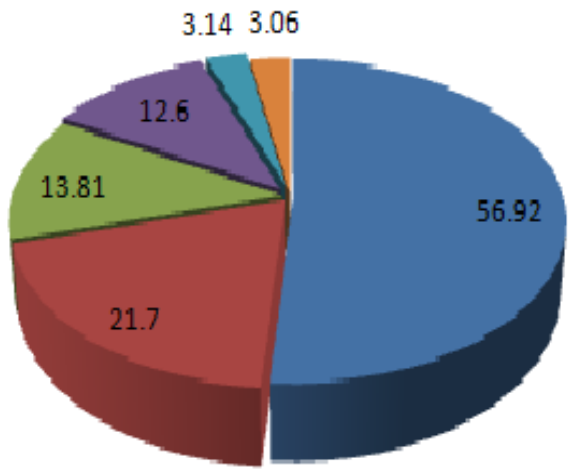

Growth factors (56.92) Hormones (21.7) Cytokines (13.81) Fusion Proteins (12.6) Plasmatic factor (3.14) Enzymes (3.06)

Fig 2: Commercial demand of therapeutic proteins in different forms

\section{Invitro Protein Expression Strategy}

Protein expression is a natural phenomenon in every living organism to maintain cell viability and physiology $[16,17]$. With the developed technologies the natural process has tuned artificially in specific cells known as host expression system. The expression of any gene runs under specific nucleotide sequences which bind RNA polymerase known as promoter sequence [18]. The promoter sequence which provide platform for RNA polymerase can be classify in natural promoter which usually express protein in threshold level while certain promoter which basically isolated from viral origin provides high level expression known as strong promoter $[19,20]$.

In case of expression of protein outside the native host one must need a carrier molecule called as plasmid or vector, possess basic requirement for protein translation. These carrier molecules as per their application classified cloning vector system used for only cloning and expression vector system which ment for expression of proteins $[21,22]$. The expression vector system essentially contains high strong promoter generally from viral origin. Frequently used promoters in different expression vector system are CMV and T7 which have been isolated from Cauliflower mosaic virus and T7 bacteriophage respectively [23, 24]. 


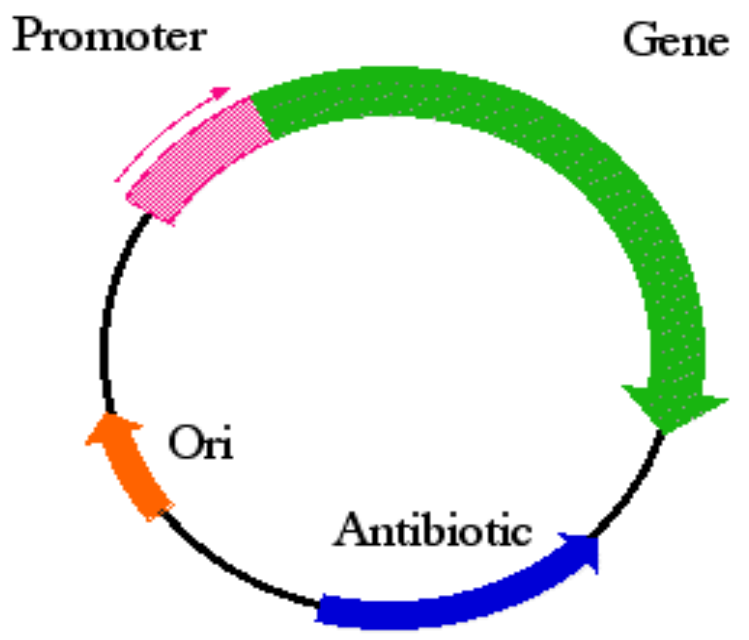

Fig 3: Layout of plasmid, three basic requirements for functionality of plasmid system, Origin of replication, Promoter allow RNA polymerase to bind and initiate translation and multiple cloning sites for cloning of gene

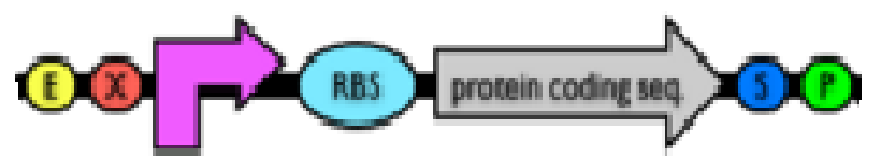

Fig 4: A cassette essentially requires for translation of recombinant protein constituted in each of plasmid/ vector used for expression

The choice of an expression system for the high-level production of recombinant proteins depends on many factors. These include cell growth characteristics, expression levels, intracellular and extracellular expression, and biological activity of the target protein [25]. In addition, the selection of a particular expression system requires a cost down in terms of process, design, and other economic consideration. The combination of recombinant DNA technology and large-scale culture process has enabled recombinant proteins to be produced in massive quantities [26]. High cell density culture techniques for culturing $E$. coli have been developed to improved productivity and also to provide advantages such as reduced culture volume, enhanced downstream process, reduced wastewater, lower production costs and reduced investment in equipment [27,28].

\section{Complications with conventional Expression system}

The complications started while the expression studies for eukaryotic proteins in E. coli expression systems during 1980 [29, 30]. The E. coli expression system lacks many codons essentially requires for the expression of eukaryotic protein and also lack post translational modification machinery for biological activity and some other complex proteins containing multiple disulfide bonds [31, 32, 33]. In addition to codon bias and lack of post translational modification machinery, many proteins expressed in E. coli got accumulated intracellular as inactive inclusion bodies [34, 35]. Expressed protein in the form of inclusion bodies further needs protein renaturation and refolding to retain biological activity, all these transformations are often complicated and costly while running denaturation and refolding process [36].

To tackle these complications attributed by $E$. coli expressions system number of animal and plant expression system have designed [37, 38]. Though these engineered expression system have made significant contribution for expression of eukaryotic proteins often failed in E. coli system but again failed to design the simple and efficient, high-yield, low-cost methods which can be used for the production of proteins in large amount [39]. Further advancement of technologies especially in protein engineering and recombinant DNA technology led to development of new generation E. coli expression system competent expression of various proteins [40]. These engineered E. coli expression system designed with certain molecule; chaperons, foldases etc allows expressed protein to retain active structure and also helps translocation from cytoplasm to periplasm and subsequently outside of cell $[41,42]$. 


\section{New Generation Expression system}

In order to meet with industrial demand expression of recombinant protein is best method ever opted. This method is not only produce protein in high fold also we easy to manipulate [43]. Many expression host systems were used for production of commercially important enzyme where E. coli BL21 has long history as ideal host. E. coli BL21 (DE3) strains provide reliable expression of many proteins cloned into T7 expression vectors (e.g., pET, pRSET etc) $[44,45]$. Though, numbers of recombinant protein expressed successfully in BL 21 (DE3) but over expression could not achieve yet [46]. Even in many cases expression is minimal or no detectable because the recombinant proteins, when expressed, become deleterious or lethal to these standard BL21 strains. Hence to achieve successful expression and over expression led to design of new engineered strains capable of over expression beyond these complications [47].

Recently, many E. coli strains C41 (DE3), C43 (DE3) and E. coli Rosetta strains have been developed that allow high level of expression to the variety of proteins previously difficult or impossible to express in bacteria E. coli BL21 [48]. These all strains are genetically engineered ensuring following parameters-

a- An ideal expression system for majority of recombinant protein.

b- To overcome toxicity exhibited by protein itself.

c- Offers expression for both prokaryotic and eukaryotic proteins (Rosetta).

d- Easy to regulate and cost factors.

\subsection{Escherichia coli BL Series}

With the advance technologies in molecule biology led to redesign existing BL21 (DE 3) strain in order to overcome drawback arises for expression of recombinant proteins. BL 41 (DE 3) and BL 43 (DE3) strains have designed for over express protein where strains contain genetic mutations phenotypically selected for conferring toxicity tolerance which blocks expression in conventional host system [49]. The strain C41 (DE3) was derived from BL21 (DE3) [E. coli F- ompT hsdSB (rB- mB-) gal dcm (DE3)]. This strain has been designed with one uncharacterized mutation that prevents cell death associated with expression of many toxic recombinant proteins [50]. Another strain C43 (DE3) was derived from C41 (DE3) by selecting for resistance to a different toxic protein which was not present in C41 (DE3). From the study it was found C43 (DE 3) had shown ability to express a different set of toxic proteins than C41 (DE3) [51].

Further, neither strain contains any plasmid or antibiotic resistance markers. However, these two strains were found different from each other and from BL21 (DE3) by study based on transfection with a plasmid verification vector, pAVD10. The vector system PAVD10 comprise of uncF gene (it encodes beta-subunit of $E$. coli ATPase) under the regulation of T7 promoter. Subsequently, this plasmid was found to lethal for BL21 (DE3) and to induced C41 (DE3), but it is tolerated by C43 (DE3) regardless of induction [52, 53].

Conventionally E.coli BL21 (DE3) strains and genetically engineered E. coli C41 (DE3) and E.coli C43 (DE3) strains for over expression contain Lambda DE3 lysogen, which expresses T7 RNA polymerase from the lacUV5 promoter under IPTG induction. Following strains can be used to express any gene cloned into a plasmid downstream to T7 promoter [54]. While the engineered strains C41 (DE3) and C43 (DE3) for over expression posses Chloramphinicol-resistant plasmid that encodes T7 lysozyme, which is a natural inhibitor of T7 RNA polymerase. These engineered strains which produce T7 lysozyme that suppresses basal expression of T7 RNA polymerase prior to induction, thus providing additional stability for recombinants encoding particularly toxic proteins [55 56].

\subsection{Escherichia coli Rosetta Series}

Codon bias in another major problem often encountered while expressing recombinant protein in many expression host system [57]. During the translation majority of amino acids are encoded by more than one codons, and each organism carries its own bias in the usage of the 61 available amino acid codons. In every cell, the population of t-RNA closely reflects the codons bias of the mRNA population [58]. When the mRNA of heterologous target genes are over expressed in E. coli, differences in codon usage can block translation due to the demand for one or more t-RNAs that may be rare or lacking in that particular population [59]. Insufficient tRNA pools can lead to translational stalling, premature translation termination, translation frame shifting and amino acid misincorporation [60].

To overcome with codon bias many attempt have been made by optimizing codons for expression of recombinant protein. Optimization of codons for each host system is not easy, time consuming and much complicated. A novel host system has been designed with universal codons which not only allow expression but also increases expression yield [61]. Rosetta host strains has deigned to fulfill all these requirements and derived from BL21 derivatives designed to enhance the expression of proteins that contain codons rarely used in E. coli [62]. The Rosetta strains supply t-RNAs for the codons AUA, AGG, AGA, CUA, CCC, and GGA on a 
compatible chloramphenicol-resistant plasmid, pRARE. Newly Rosetta strains also supply a seventh rare codons (CGG) in addition to the six found in the original Rosetta strains [63]. By supplying following rare codons, Rosetta strains provide a "universal" translation, where translation would otherwise be limited by the codons usage of E. coli. In few Rosetta strains like pLysS and pLacI the rare t-RNA genes are present on the same plasmids that carry the T7 lysozyme and lac repressor genes respectively $[64,65]$.

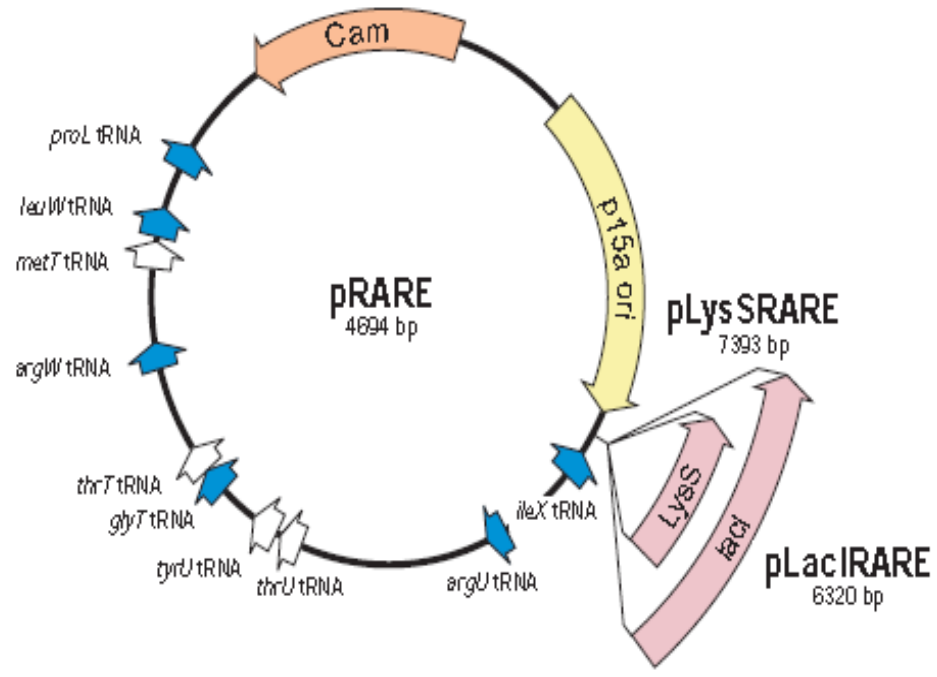

Fig 5: Plasmid pRARE essentially constructed in Rosetta, it enables Rosetta for the expression of protein often get fails in conventional expression host system.

Simultaneously, pRIG plasmid transformed into pRARE by incorporating rare E. coli codons leuW and proL t-RNA genes which improve expression level often not present in any of E. coli strains naturally [66]. While plasmid pRARE is capable for encoding t-RNA genes for all of the "problematic" rarely used codons encoding Arg, Ile, Gly, Leu and Pro, except for Arg CGA/CGG [67]. The entire rare t-RNA assembly was incorporated to the pLysS and pLacI plasmids which were derived from pACYC184 to construct pLysSRARE and pLacIRARE, respectively [68]. The plasmids were transformed into various strains to create the Rosetta series of expression hosts. These host strains enhance protein expression from target genes containing rare $E$. coli codons that would otherwise impede translation [69]. Rosetta pLysS and Rosetta-gami-pLysS are two new variant in this series with slight modifications engineered for over expression of eukaryotic proteins [70].

\section{Commercially available high level expression host system}

Lack of natural proteins, which used in many areas like therapeutics, industry and analytical triggered for finding alternative methods for production of these amazing molecules. Commercial demand and industrial application of recombinant proteins led to develop numbers of new host system and majority of them are in use. These new generation host system expressed many essential protein in higher amount. Enormous expression systems are in the commercial market from various producers to achieve desired protein expression. In the following table the most common host expression systems which are in use summarized as- 
New Generation Expression Host System- Aiming high for commercial production of recombinant protein

\begin{tabular}{|c|c|c|c|}
\hline S. No. & Strain & Company & Technical information \\
\hline 1. & BL21 (DE3) & Novagen & $\begin{array}{c}\text { Expression under IPTG Induction Ideal for } \\
\text { prokaryotic protein } \\
\text { Contains T7 polymerase }\end{array}$ \\
\hline 2. & $\begin{array}{c}\text { BL21 (DE3) } \\
\text { pLysS }\end{array}$ & Novagen & $\begin{array}{c}\text { Expression under IPTG Induction Ideal for } \\
\text { prokaryotic protein } \\
\text { Contains T7 polymerase }\end{array}$ \\
\hline 3. & C41 (DE3) & Lucigen & $\begin{array}{c}\text { Exhibit Over expression } \\
\text { Both prokaryotic protein and eukaryotic } \\
\text { proteins }\end{array}$ \\
\hline 4. & C43 (DE3) & Lucigen & $\begin{array}{c}\text { Both prokaryotic protein and eukaryotic } \\
\text { proteins }\end{array}$ \\
\hline 5. & BLR & Novagen & $\begin{array}{c}\text { recA- variant of BL 21 } \\
\text { Maintain protein stability }\end{array}$ \\
\hline 6. & Rosetta & Lucigen & $\begin{array}{c}\text { pRARE plasmid offer essential tRNA for } \\
\text { eukaryotic protein }\end{array}$ \\
\hline 7. & Rosetta pLysS & Lucigen & $\begin{array}{c}\text { pRARE plasmid offer essential tRNA for } \\
\text { eukaryotic protein }\end{array}$ \\
\hline 8. & $\begin{array}{c}\text { Rosetta gami } \\
\text { pLysS }\end{array}$ & Lucigen & $\begin{array}{c}\text { pRARE plasmid offer essential tRNA for } \\
\text { eukaryotic protein }\end{array}$ \\
\hline 9. & AD494 & Novagen & trx mutant of K 12 Allow protein folding \\
\hline 10. & Tuner pLysS & Novagen & $\begin{array}{c}\text { Contains pLysS plasmid allow higher level } \\
\text { of expression }\end{array}$ \\
\hline
\end{tabular}

\section{Conclusions}

The recent increasing demand of various protein molecules in industries and therapeutics triggered development of new technologies to fulfill commercial consumption. Design of high level expression host systems which not only express recombinant protein to bulk but also provide universal system where different types of protein can be produced without any complications. Though these engineered expression systems have made much remarkable contribution in the field of protein expression but still lot of optimization studies needed. The major challenges which need to achieve these systems are ease of handling, universal application and cost of these engineered hosts. If we could achieve these challenges, this will make a new era in the molecular biology regarding commercial production of recombinant proteins.

\section{References}

[1]. Crommelin, D. J. A.; Sindelar, R. D.; Meibohm, B. Pharmaceutical Biotechnology; $3^{\text {rd }}$ ed.; Informa Healthcare: New York,2008.

[2]. Devlin TM (1986). Textbook of Biochemistry with Clinical Correlations,(2ndEdition), John Wiley and Sons, Inc., New York, USA, p. 165.

[3]. Coombs J (1992). Dictionary of Biotechnology, Second Edition. Stockton Press, 257 Park Avenue South, New York, 10010, USA, p.555.

[4]. White JS, White DC (1997). Source book of enzymes. Boca Raton, CRC Press.

[5]. Alex K Pavlou and Janice M Reichert. 2004. Recombinant protein therapeutics- success rates, market trends and values to 2010. Nature Biotechnology. 22: 1513-1519.

[6]. Fischer R, Drossard J, Commandeur U, Schillberg S and Emans N (1999a) Toward molecular farming in the future: Moving from diagnostic protein and antibody production in microbes to plants.Biotechnol Appl Biochem 30: 101-108.

[7]. Robinson, M., et al. , 1984. Codon usage can affect efficiency of translation of genes in Escherichia coli. Nucleic Acids Res. $12(17), 6663-6671$

[8]. Sharp, P.M., Li, W.-H., 1986. Codon usage in regulatory genes in Escherichia coli does not reflect selection for rare codons. Nucleic Acids Res. 14, 7737 - 7749.

[9]. Urrutia, A.O., Hurst, L.D., 2001. Codon usage bias covaries with expression breadth and the rate of synonymous evolution in humans, but this is not evidence for selection. Genetics 159, $1191-1199$.

[10]. Urrutia, A.O., Hurst, L.D., 2003. The signature of selection mediated by expression on human genes. Genome Res. 13 (10), $2260-2264$.

[11]. GUPTA, R.; BEG, Q.K. and LORENZ, P. Bacterial alkaline proteases: molecular approaches and industrial applications. Applied Microbiology and Biotechnology, April 2002, vol. 59, no. 1, p.15-32.

[12]. Godfrey T, West S (1996) Introduction to industrial enzymology.In: Godfrey T, West S (eds) Industrial enzymology, 2nd ed.Macmillan Press, London, pp 1-8.

[13]. Aunstrup K (1980) Proteinases. In: Rose AH (ed) Microbial enzymes and bioconversions. Academic Press, New York, pp 50114. 
[14]. Restifo N, Rosenberg S. Developing recombinant and synthetic vaccines for the treatment of melanoma. Curr Opin Oncol 1999;11:50-7.

[15]. Xu G, McLeod H: Strategies for enzyme/prodrug cancer therapy. Clin Cancer Res 2001, 7:3314-3324.

[16]. Davis, G.D., Elisee, C., Newham, D.M., Harrison RG, 1999. New fusion protein systems designed to give soluble expression in Escherichia coli. Biotechnol. Bioeng. 65, 382-388.

[17]. Del Solar, G., Giraldo, R., Ruiz-Echevarria, M.J., Espinosa, M., DiazOrejas R, 1998. Replication and control of circular bacterial plasmids. Microbiol. Mol. Biol. Rev. 62, 434-464.

[18]. Baneyx, F., 1999. Recombinant protein expression in Escherichia coli. Curr. Opin. Biotechnol. 10, 411-421.

[19]. Bentley, W.E., Kompala, D.S., 1990. Optimal induction of protein synthesis in recombinant bacterial cultures. Ann. N. Y. Acad. Sci.589, 121-138.

[20]. Blight, M.A., Chervaux, C., Holland, I.B., 1994. Protein secretion pathway in Escherichia coli. Curr. Opin. Biotechnol. 5, 468-474.

[21]. Calderone, T.L., Stevens, R.D., Oas, T.G., 1996. High-level misincorporation of lysine for arginine at AGA codons in a fusion protein expressed in Escherichia coli. J. Mol. Biol. 262, 407-412.

[22]. Calos, M.P., 1978. DNA sequence for a low-level promoter of the lac repressor gene and an 'up' promoter mutation. Nature $274,762-765$.

[23]. Cao, G.J., Pogliano, J., Sarkar, N., 1996. Identification of the coding region for a second poly(A) polymerase in Escherichia coli. Proc.Natl. Acad. Sci. U. S. A. 93, 11580-11585.

[24]. Carbonell, X., Villaverde, A., 2002. Protein aggregated into bacterial inclusion bodies does not result in protection from proteolytic digestion. Biotechnol. Lett. 24, 1939-1944.

[25]. Held, D., Yaeger, K. \& Novy, R. New co-expression vectors for expanded compatibilities in E. coli. inNovations 18, 4-6 (2003).

[26]. Ho, T.Q., Zhong, Z., Aung, S. \& Pogliano, J. Compatible bacterial plasmids are targeted to independent cellular locations in Escherichia coli. EMBO J. 21, 1864-1872 (2002).

[27]. Li, C., Schwabe, J.W., Banayo, E. \& Evans, R.M. co-expression of nuclear receptor partners increases their solubility and biological activities. Proc. Natl. Acad. Sci. USA 94, 2278-2283 (1997).

[28]. Held, D., Yaeger, K., Novy, R., 2003. New co-expression vectors for expanded compatibilities in E. coli. InNovations 18, 4-6.

[29]. Horvath H, Huang JT, Wong O, et al., The production of recombinant proteins in transgenic barley grains, P NATL ACAD SCI USA 97 (2000), pp. 1914-1919.

[30]. Woo JH, Liu YY, Mathias A, et al., Gene optimization is necessary to express a bivalent anti-human anti-T cell immunotoxin in Pichia pastoris, PROTEIN EXPRES PURIF 25 (2002), pp. 270-282.

[31]. Sinclair G, Choy FYM, Synonymous codon usage bias and the expression of human glucocerebrosidase in the methylotrophic yeast, Pichia pastoris, PROTEIN EXPRES PURIF 26 (2002), pp. 96-105.

[32]. Kim CH, Oh Y, Lee TH, Codon optimization for high-level expression of human erythropoietin (EPO) in mammalian cells, GENE 199 (1997), pp. 293-301.

[33]. Horvath H, Huang JT, Wong O, et al., The production of recombinant proteins in transgenic barley grains, P NATL ACAD SCI USA 97 (2000), pp. 1914-1919.

[34]. Ikura, K., Kokubu, T., Natsuka, S., Ichikawa, A., Adachi, M., Nishihara, K., Yanagi, H., Utsumi, S., 2002. Co-overexpression of folding modulators improves the solubility of the recombinant guinea pig liver transglutaminase expressed in Escherichia coli. Prep. Biochem. Biotechnol. 32, 189-205.

[35]. Jacquet, A., Daminet, V., Haumont, M., Garcia, L., Chaudoir, S.,Bollen, A., Biemans, R., 1999. Expression of a recombinant Toxoplasma gondiiROP2 fragment as a fusion protein in bacteria circumvents insolubility and proteolytic degradation. Protein Expr. Purif. 17, 392-400.

[36]. Jonasson, P., Liljeqvist, S., Nygren, P.A., Stahl, S., 2002. Genetic design for facilitated production and recovery of recombinant proteins in Escherichia coli. Biotechnol. Appl. Biochem. 35,91-105.

[37]. Pedelacq, J.D., Piltch, E., Liong, E.C., Berendzen, J., Kim, C.Y., Rho,B.S., Park, M.S., Terwilliger, T.C., Waldo, G.S., 2002. Engineering soluble proteins for structural genomics. Nat. Biotechnol. 20,927-932.

[38]. Nishihara, K., Kanemori, M., Yanagi, H., Yura, T., 2000. Overexpression of trigger factor prevents aggregation of recombinant proteins in Escherichia coli. Appl. Environ. Microbiol. 66, 884-889.

[39]. Novy, R., Yaeger, K., Mierendorf, R., 2001. Overcoming the codon bias of E. coli for enhanced protein expression. InNovations 12, 1-3.

[40]. F. Ulrich Hartl, Andreas Bracher \& Manajit Hayer-Hartl Molecular chaperones in protein folding and proteostasis Nature 475, 324-332 (21 July 2011).

[41]. Davison, J. Mechanism of control of DNA replication and incompatibility in ColE1-type plasmids-a review. Gene 28, 1-15 (1984).

[42]. Sørensen, H.P., Sperling-Petersen, H.U., Mortensen, K.K., 2003b. A favorable solubility partner for the recombinant expression of streptavidin. Protein Expr. Purif. 32, 252-259.

[43]. Miroux, B., Walker, J.E., 1996. Over-production of proteins in Escherichia coli: mutant hosts that allow synthesis of some membrane proteins and globular proteins at high levels. J. Mol. Biol.260, 289-298.

[44]. F.W. Studier, A.H. Rosenberg, J.J. Dunn, J.W. DubendorV, Use of T7 RNA polymerase to direct expression of cloned genes, Methods Enzymol. 185 (1990) 60-89.

[45]. J. Voet-van-Vormizeele, G. Groth, High-level expression of the Arabidopsis thaliana ethylene receptor protein ETR1 in Escherichia coli and puriWcation of the recombinant protein, Prot. Expr. Purif. 32 (2003) 89-94.

[46]. Mayer, M.P., 1995. A new set of useful cloning and expression vectors derived from pBlueScript. Gene 163, 41-46.

[47]. Steinfels, E., Orelle, C., Dalmas, O., Penin, F., Miroux, B., Di Pietro, A., Jault, J.M., 2002. Highly efficient over-production in E. coli of YvcC, a multidrug-like ATP-binding cassette transporter from Bacillus subtilis. Biochim. Biophys. Acta 1565, 1-5.

[48]. Dubendorff, J.W., Studier, F.W., 1991. Controlling basal expression in an inducible T7 expression system by blocking the target T7 promoter with lac repressor. J. Mol. Biol. 219, 45-59.

[49]. Lee, S. Y., "High cell density cultivation of Eshcherichia coli" Trands Biotechnol. 14:98-105 (1996).

[50]. Jeong, K. J., Lee, H. S., Lee, S. Y. and Chang, H. N., "Development of recombinant bacteria for the degradation of dibenzothiophene" Ann. NY Acad. Sci., 864:375-378 (1998). 
[51]. Park, S. J. and Lee, S. Y., "Efficient recovery of secretory recombinant protein from protease negative mutant Eshcherichia coli" Biotechnol. Techniques, 64(12):4897-4903 (1998).

[52]. Kim, Y. C., Kwon, S., Lee, S. Y. and Chang, H. N., "Effect of pLysS on the production of bioadhesive precursor protein by fed-batch cultivation of recombinantEshcherichia coli" Biotechnol. Lett. 20(8):799-803 (1998).

[53]. Park. S.J., Georgiou, G. and Lee, S.Y. "Secretory production of recombinant protein by high cell density culture of protease negative mutant Escherichia coli strain", Biotechnol. Prog. 15(2): 164-167 (1999).

[54]. Xu, Z. and Lee, S.Y. "Display of poly-His peptides on Escherichia coli cell surface using outer membrane protein C (OmpC) as an anchoring motif", Appl.Environ.Microbiol. 65:363-368 (1999).

[55]. Jeong, K.J., and Lee, S.Y. "Secretory Production of human leptin in Escherichia coli", Biotechnol. Bioeng. 67:398-407 (2000).

[56]. Choi, J. H., Jeong, K. J., Kim, S. C. and Lee, S. Y. "Efficient secretory production of alkaline phosphatase by high cell density culture of recombinant Escherichiacoli using the Bacillus sp. Endoxylanase signal sequence" Appl. Microbiol. Biotechnol. 53:640-645 (2000).

[57]. Xu, Z., Lee, S. Y and Yu. Z. "Physiological characteristics of recombinant Eshcerichia coli cells displaying poly-His peptides" Biotechnol. Lett 21:1091-1094 (2000).

[58]. Jeong, K.J. and Lee, S.Y. Secretory production of human leptin in Bacillus subtilis \pm J. Microbiol. Biotechnol. 10(6):753-758 (2000).

[59]. Jeong, K.J. and Lee, S.Y. "Secretory production of human granulocyte-colony stimulating factor in Escherichia coli", Protein Expres. Purif., 23(2):311-318, November (2001).

[60]. Yim, S.C., Jeong, K. J., Chang, H.N. and Lee. S.Y. ; ${ }^{\circ}$ High level secretory production of human G-CSF by fed-batch culture of recombinant Escherichia coli \pm , Bioprocess Biosystems Eng., 24:249-254 (2001).

[61]. Kim, R., Sandler, S.J., Goldman, S., Yokota, H., Clark, A.J., Kim, S.H., 1998. Overexpression of archaeal proteins in Escherichia coli. Biotechnol. Lett. 20, 207-210.

[62]. Wu, X., Jornvall, H., Berndt, K.D., Oppermann, U., 2004. Codon optimization reveals critical factors for high level expression of two rare codon genes in Escherichia coli: RNA stability and secondary structure but not tRNA abundance. Biochem. Biophys. Res. Commun. 313, 89-96.

[63]. Carrio, M.M., Cubarsi, R., Villaverde, A., 2000. Fine architecture of bacterial inclusion bodies. FEBS Lett. 471, 7-11.

[64]. Davis, G.D., Elisee, C., Newham, D.M., Harrison RG, 1999. New fusion protein systems designed to give soluble expression in Escherichia coli. Biotechnol. Bioeng. 65, 382-388.

[65]. Kuczynska-Wisnik, D., Kedzierska, S., Matuszewska, E., Lund, P., Taylor, A., Lipinska, B., Laskowska, E., 2002. The Escherichia coli small heat-shock proteins IbpA and IbpB prevent the aggregation of endogenous proteins denatured in vivo during extreme heat shock. Microbiology 148, 1757-1765.

[66]. http://wolfson.huji.ac.il/expression/bac-strains-prot-exp.html

[67]. http://wolfson.huji.ac.il/expression/procedures/bacterial/novagen-CompCells.pdf

[68]. Ritz, D., Lim, J., Reynolds, C.M., Poole, L.B. and Beckwith, J. (2001) Science 294, 158-160.

[69]. Del Tito, B.J., Jr., Ward, J.M., Hodgson, J., Gershater, C.J., Edwards, H., Wysocki, L.A., Watson, F.A., Sathe, G. and Kane, J.F. (1995) J. Bacteriol. 177, 7086-7091.

[70]. Sørensen, H.P., Laursen, B.S., Mortensen, K.K., Sperling-Petersen, H.U., 2002. Bacterial translation initiation-mechanism and regulation. Recent Res. Dev. Biophys. Biochem. 2, 243-270. 